\title{
THE TECHNIQUE FOR AUTOMATED EXTRACTION OF CONTEXTUAL KNOWLEDGE FROM INFORMATION RESOURCES OF TEXT MODALITY
}

\author{
Olga Kononova ${ }^{1}$, Dmitry Prokudin ${ }^{1,2}$, and Elena Yelkina ${ }^{1}$ \\ ${ }^{I}$ St. Petersburg National Research University of Information Technologies, Mechanics and Optics (ITMO University) \\ 197101, St. Petersburg, Russia \\ ${ }^{2}$ St. Petersburg State University 199034, St. Petersburg, Russia
}

\begin{abstract}
Dynamics of social development leads to formation of various cross-disciplinary scientific directions influencing both social development and transformations of scientific research. Development of the interdisciplinary scientific directions during the digital era is connected with the level of development and uses of technologies in information society, tools and network environments of scientific work support. The purpose of the conducted research is the integrated approach creation to the analysis of a terminology database of the developing interdisciplinary research in the distributed network environment. The research has been conducted on the arrays of information received from various digital sources including scientific publications for the last 10 years and the maintenance of social and public discourse (for example, publications in Media). Results of the analysis of Russian (e-Library) and English scientific publications (Scopus, Science Direct) on the subject are presented in the offered article for the direction "Digital Economy: e-Governance and Smart Technology" for the period of 2008-2018. The relevance of the subject chosen is caused by the beginning of the Program "Digital Economy of the Russian Federation" realization which publication results in repeated interest increase in subject both from media and scientific environment. The possibility of the scientific technique application developed by the authors on the information resources of text modality is suggested in the article. The technique is based on the integrated approach (the Synthetic Method) to the selection of digital information resources, extraction and the analysis of contextual knowledge and allows specifying terminology database of the formed interdisciplinary scientific direction "Digital Economy: e-Governance and Smart Technology". Russian-language distributed environment for scientific research T-Libra and multilingual Voyant-Tools are used as the tools for search, explication, and analysis of contexts.
\end{abstract}

\section{KEYWORDS}

Digital Economy, Digital Technology, Smart Technology, Contextual Knowledge Extraction, Information Resources, Contextual Search, Terminological Landscape, Machine Learning

\section{INTRODUCTION}

A high level and the availability of digital technology that increases the amount of information in digital format and the intensification of information exchange are characterized by the modern information society. The emergence of new information and its exchange occur so quickly that the traditional life cycle of innovations undergoes various transformations. One can no longer be sure that innovations, including the new terminology, were born in a science environment and further embedded in the society. The topics received initial dissemination as a state, community or business initiatives become source of wide scientific discourse. Socio-political and official (state) discourse, which is reflected in Mass Media, has a direct influence on the development of terminology-base interdisciplinary scientific directions. Digitalization of research results updates the terminology research landscape of these trends, explication, and interpretation of contextual knowledge. All the above mentioned fully applies to the analysis of the modern research-based content. The analysis allows predicting the occurrence of research topics (contextual knowledge), their relevance in various subject domains using methods, approaches, technologies, and tools of Digital Humanities. 
This paper suggests the interdisciplinary scientific research direction "Digital Economy: e-Governance and Smart Technology". In accordance with the social development tendencies, the trend has spread in the world and in the past few years emerged in Russia. In Russia, this trend was developed at first as a State initiative. The initiative emerged because of the prerequisites for the transition to the new model of social development. Therefore, from our point of view, the social and political changes, as well as formation of digital culture should be considered in the study of interdisciplinary landscape terminology scientific directions.

\section{CONTEXTUAL KNOWLEDGE: IDEAS AND APPROACHES TO SYSTEMATIZATION}

Comparative analysis of context concept definitions promotes systematization of ideas and developments in the field of study, extraction, and use of contextual knowledge (van Dijk, 2005; Jakubczyc and Owoc, 2011). On the whole, the definition of the concept and types of contexts reflects: 1) the specificity of the subject areas of scientific and unscientific knowledge (Explanatory Dictionary, 2019; Esin, 2000; Sinclair \& Rockwell, 2015); 2) types of information bearer (text or non-textual modality of information) (Bhargava \& Rashmi Sharma, 2010; Suchkova, 2010); 3) metaphorical term transfer from scientific field to the various discourse social practice (Shilov \& Yermolayev, 2016).

In this study, the authors are not interested in all typological characteristics of the context species, but mainly in the contexts defined by the way of their explication - horizontal micro-context (within the author's paragraph) and vertical macro-context (in the frames of a document or a set of documents). These types of contexts can be used to identify clusters of contextual knowledge associated with the term-concepts. The authors define context as an independent conceptual unit of categorical apparatus, which can be the basis for classification of scientific texts and represents a dynamic mechanism of meaning and values formation (definition of hierarchical and associative relationships of interdisciplinary ontology).

The authors introduce such new types of contextual knowledge as 'term-concept' and 'subject-thematic trend'. 'A term-concept' is an interpreter of meanings and values by summing up the term under certain categories and classes, a basic unit of information storage and transmission. The other two types - 'corpus' (a set of key term-concepts) and 'thesaurus' (a set of thematically organized terms within the same subject area) represent the upper levels of contextual knowledge classification.

The study of contextual knowledge "responsible" for the "ontic innovation" (Karpov, 2008, p. 86) is related to the analysis of the concept's correlation: 'contextual knowledge' - 'term-concept' - 'context model' - 'contextual knowledge structure' - 'subject-thematic trend' - 'corpus' - 'thesaurus' - 'discourse' (Kononova, Lyapin \& Prokudin, 2018). The attribute context characteristics are the meanings and values of terms (concepts) and situations. A set of concepts are organized in hierarchical semantic networks. A set of thematically organized terms within the same subject area (it may be interdisciplinary) forms the thesaurus of a subject field or interdisciplinary ontology. In the framework of the interdisciplinary trend "Digital Economy: e-Governance and Smart Technology," we investigate the development of the interdisciplinary ontology of this domain. For this objective, we define the interaction of the basic term-concepts and their contexts: 'digital technology', 'smart technology', 'e-government', 'e-governance', 'Digital Economy' and the others. For this purpose, various tools are used to explicate contextual knowledge from distributed information networks that contain scientific and Media Texts.

The formation of new interdisciplinary trends based on an automated explication of thesauri is a promising field of scientific and methodological research. The implementation of contextual knowledge-based and concept-based query formulation techniques is regarded in (Limbu, Pears, Connor $\&$ MacDonel, 2006). The problem of different levels of contextual knowledge and its classification is discussed in (Jakubczyc \& Owoc, 2011). 


\section{THE TECHNIQUE FOR CONTEXTUAL KNOWLEDGE EXTRACTION}

\subsection{The Digital Economy Program and the Basic Key Term-Concepts}

To identify a list of the key terminology domain, the trend of interdisciplinary scientific research "Digital Economy: e-Governance and Smart Technology" the analysis of information obtained from open sources was made. Basic arrays were obtained from the Russian scientific electronic library (http://elibrary.ru), full-text database of Media publications (more than 1000 Russian newspapers and magazines at the Federal and Regional levels represented on the platform Integrum (https://integrum.ru).

The preliminary stage of the current research is the selection of the terminological core of the subject domain "The Digital Economy." The analysis of the Program "Digital Economy of the Russian Federation" (approved by the Decree of the Russian Federation Government dated July 28, 2017, № 1632-p) was carried out to initially identify interdisciplinary direction corpus of "Digital Economy: e-Governance and Smart Technology." Analysis of the submitted semantic core reveals that Digital Economy in the field of e-Public Administration continues the development of ideas and projects, which have started developing in Russia since 2005 and can be characterized by the term-concepts: 'public administration', 'e-governance', 'e-state', 'state information system'. In the field of both interdisciplinary directions development as "The Public Administration" and "The Digital Economy" the term-concept "public services' (including "municipal services') is more frequently used (Table 1).

Table 1. Distribution of scientific and Mass Media publications on the term-concept 'Digital Economy'

\begin{tabular}{llllllllllllll}
\hline Year & 2005 & 2006 & 2007 & 2008 & 2009 & 2010 & 2011 & 2012 & 2013 & 2014 & 2015 & 2016 & 2017 \\
\hline eLibrary & 0 & 0 & 1 & 5 & 2 & 6 & 16 & 15 & 20 & 27 & 60 & 148 & 1268 \\
\hline Media & 12 & 7 & 0 & 8 & 6 & 8 & 18 & 30 & 39 & 48 & 82 & 308 & 3833 \\
\hline
\end{tabular}

The analysis of the semantic core of the interdisciplinary scientific research trend "Digital Economy: e-Governance and Smart Technology" makes it clear, that the term-concept 'digital technology' is the development of the Russian studies and approaches in the last twenty years. It is characterized by stable ties with the following term-concepts: 'public administration', 'e-governance', and 'e-government information system'. The relevance score of the main term-concepts of the interdisciplinary trend "Digital Economy: e-Governance and Smart Technology" was made on the base of Russian full-text digital electronic resources: scientific publications (eLibrary, Kiberleninka, Socionet, East View); scientific, popular scientific and educational-methodical literature (ELN Lanj, East View); as well as Media - newspapers and magazines (Integrum, East View).

The analysis of eLibrary and Integrum publications indicate that the above-mentioned term-concepts began to emerge in both scientific and socio-political discourse from the early 2000-s, that corresponds to the beginning of the development of the information society in Russia as a stable public tendency (Kononova, Lyapin \& Prokudin, 2018).

\subsection{The Synthetic Method}

Automated extraction technique of contextual knowledge (the Synthetic Method) is an integrated approach oriented to solve problems of allocation and explication of scientific content on topical directions of interdisciplinary scientific research (Kononova, Lyapin \& Prokudin, 2018). The Synthetic Method uses advanced systems of full-text and multimodal search in network distributed environments. The method involves the extraction, expert evaluation, and interpretation of contextual knowledge from large text and non-text information data. This method makes it possible to enter a new level of understanding the typologies of contextual knowledge, formation, objectivization, and updating of terminology base of interdisciplinary research.

The main objective of the Synthetic Method is to explore the explication possibilities of scientific knowledge gained from the digital information resources in a distributed network environment, using methods and technologies of extraction and analysis of contextual knowledge. Unlike existing developments, expected results of the Synthetic Method applying are supposed to examine the structures and functions of 
knowledge in interdisciplinary research deeper, as well as to use the contextual framework for interpreting scientific texts, algorithm development, software intelligent search, and artificial intelligence.

The Synthetic Method displays content analysis to a higher level. In the traditional content-analysis, the target function and category analysis are of primary importance, while derived generalized text units of analysis are more important. For the Synthetic Method, a generalized text has a priority. The resulting content, structuring the description of contextual knowledge, is secondary. The traditional content-analysis and the proposed Synthetic Method are complementary technologies of context study. The text (or the text and the multimodal information) in this case is a generator of explicated contexts and contextual knowledge.

The technique allows forming thematic collections of materials (contexts, which are relevant to the research topics). A thematic collection is a result of the peer review of paragraphs obtained sequentially with the relative, and then with thematic queries.

\section{EXPERIMENTAL PART OF THE STUDY}

\subsection{Environments, Data, and the Technique Used}

To collect texts of scientific papers and publications in the Media, we used English-language (Science Direct) and Russian-language network information resources and scientific publications.

For the extraction and context-analysis of Russian full-text bases, the efforts of the researchers were concentrated on the affordable distributed network environment T-Libra.

For processing English texts, we have chosen Voyant-Tools, a web-based text reading and analysis environment. It is a scholarly project that is designed to facilitate reading and interpretive practices for students and scholars oriented on Digital Humanities, as well as for the general public (https://voyanttools.org) (Bello, Clements, Dickerson \& Hogarth, 2016; Sampsel, 2018; Rogers, 2018; Sinclair \& Rockwell, 2015; Welsh, 2014). This tool is widely used in various scientific research (Bickett et al., 2017; Lee et al., 2018; Maramba et al., 2015; Chakraborty et al., 2018).

In Voyant-Tools, the following basic tools are realized:

1. Construction of a table view of:

- term frequencies in the entire corpus or for each document;

- terms appeared more frequently in proximity to keywords across the entire corpus.

2. Provision of a rudimentary way of generating term clusters from a document or corpus and then seeing how each topic (term cluster) distributed across the document or corpus.

3. An exploration of the extent to which term frequencies vary in sync (terms which frequencies rise and fall together or inversely).

4. A show of each occurrence of a keyword with a bit of surrounding text (the context), which can be useful for studying more closely, how terms are used in different contexts.

Voyant-Tools has also a variety of means used for visualization of handled text data: representation of keywords and terms that occur in close proximity, as a force directed network graph; visualization of the frequency and distribution of terms in a corpus; visualization that depicts the change of the frequency of words in a corpus (or within a single document); a line graph depicting the distribution of word's occurrence across a corpus or document.

Because of the Synthetic Method does not depend on the instrumental environment for conducting research and the language of presentation and the text format, the technique (technology of the automated extraction and studying of contextual knowledge) validation was performed for arrays of Russian and English scientific publications. T-Libra (http://77.234.221.107/bin/TauC.exe?DSN=tlibra) for Russian texts and Voyant-Tools (https://voyant-tools.org/) for English texts were used as the tools for search, explication, and analysis of contexts.

\subsection{The Technique for the Automated Extraction and Studying Contextual Knowledge: eLibrary, T-Libra}

The text arrays of the direction "Digital Economy: e-Governance and Smart Technology" include massive of papers with term-concepts: 'Digital Economy' (DE), 'Digital Technology' (DT), 'Smart Technology' (ST), 'Information Technology', 'Governance and Administration' (IT+GaA), 'Public Services' (PS), 'Information Technology' (IT). In order to identify clusters of contextual knowledge of the subject domain the 
combination of the paragraph-oriented ("single-layer" query) and frequency-oriented (relative-frequency query) searches were used.

The expert evaluation results of the absolute frequency query for 3 baskets and 4 semantic groups were identified and classified. Semantic groups contain term-concepts with similar meanings (functional synonyms) or term-concepts with complementary meanings (forming connected pairs). The noise level was ranged from 1 to $5 \%$ for each of the baskets. The number of the key term-concepts in the text and their frequency of occurrence are presented in Figure 1.

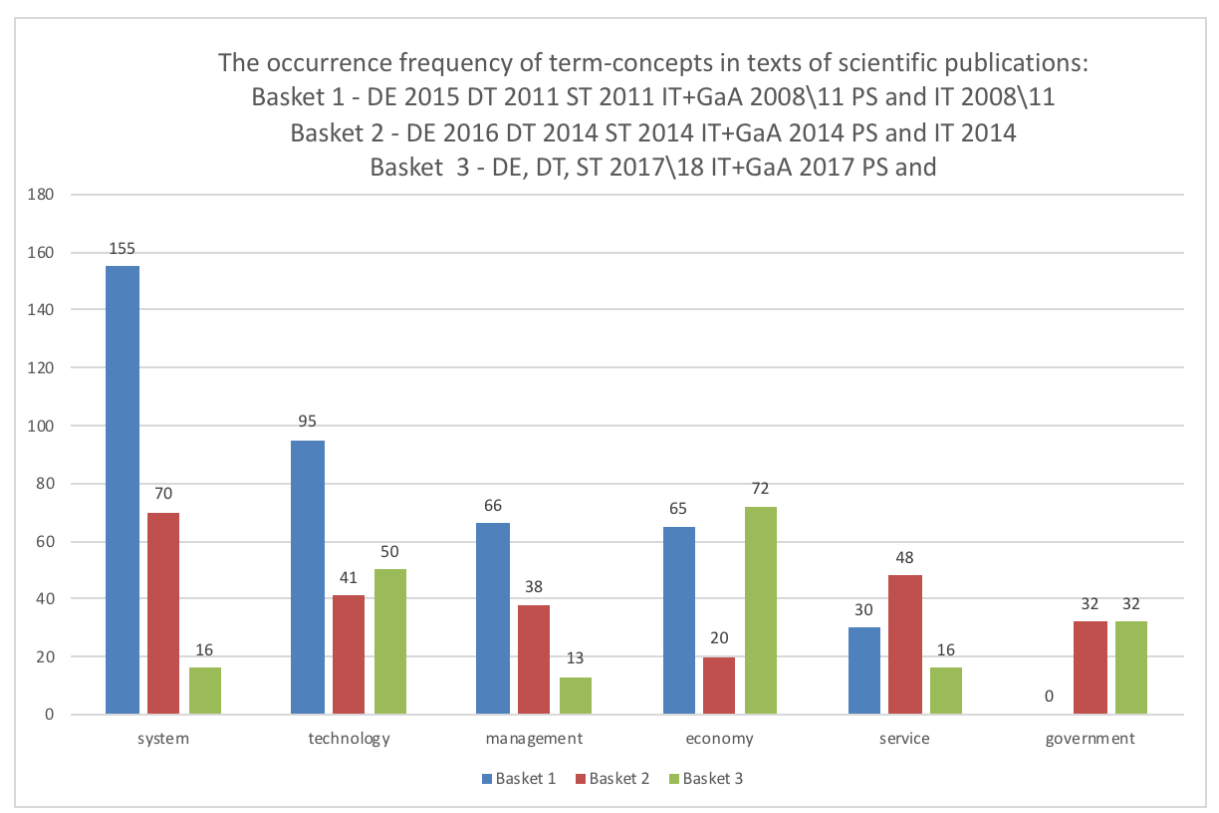

Figure 1. The occurrence frequency of the term-concepts

Selection of semantic groups: Authority ['authority'; 'state'; 'government department'; 'government']; Subjects of relationships ['citizen'; 'society'; 'business'; 'company'; 'organization'; 'enterprise']; Functional areas ['economy'; 'science'; 'development'; 'control'; 'management'; 'process'; 'production'; 'implementation'; 'sphere'; 'environment'; 'efficiency']; Technology ['system'; 'technology'; 'internet'; 'information'; 'resource'; 'structure'; 'service'; 'factor'; 'principle'; 'provision'].

The ratings of the key term-concepts having the highest frequency of appearance in the texts in each basket are presented in Figure 2.

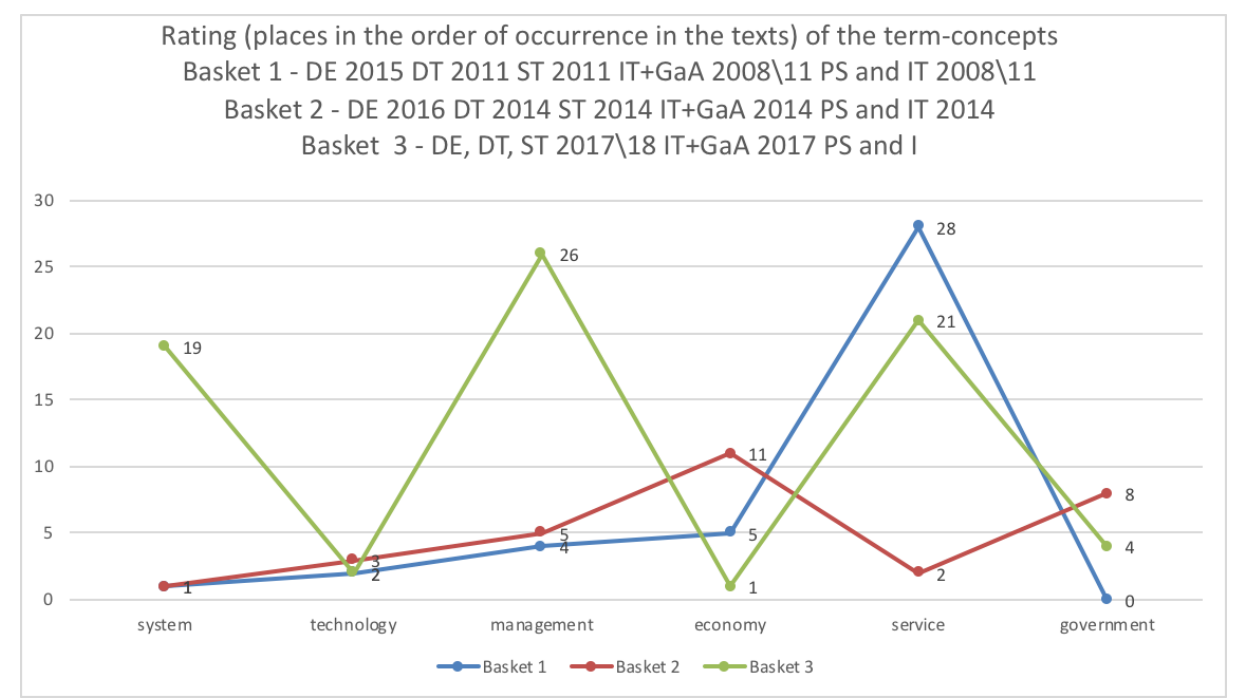

Figure 2. The rating of the term-concepts 
For the further content analysis procedures, the minimum, maximum, average, and median values of the frequencies encountered were calculated (It was done in MS Excel using the standard MIN, MAX, AVERAGE, MEDIAN functions; Table 2).

Table 2. The frequency of the terms occurrence (\%)

\begin{tabular}{cllllll}
\hline frequency in & \multicolumn{3}{l}{ Number of the terms (total) } & \multicolumn{4}{l}{ The frequency of the terms occurrence (\%o) } \\
\cline { 2 - 7 } intervals & $>2 \%$ & $1-2 \%$ Min & Max & Average & Median \\
\hline Baskets 1 & $7(576)$ & $8(309)$ & 1,028 & 5,493 & 1,708 & 1,400 \\
\hline Baskets 2 & $23(870)$ & $13(225)$ & 0,889 & 4,789 & 1,601 & 1,300 \\
\hline Baskets 3 & $7(268)$ & $23(365)$ & 1,121 & 6,724 & 1,971 & 1,588 \\
\hline
\end{tabular}

Basket 1: 7 term-concepts have the occurrence frequency above average ('system', 'technology', 'process', 'management', 'economy', 'information', 'development') and 13 term-concepts have the occurrence frequency above median (only 2 key terms: 'development', 'organization').

Basket 2: 8 term-concepts have the occurrence frequency above average (key terms: 'system', 'service', 'technology', 'management', 'resource', 'internet', 'government') and 15 term-concepts have the occurrence frequency above median (only 5 key terms: 'state', 'authority', 'development', 'government department', 'citizen').

Basket 3: 6 term-concepts have the occurrence frequency above average (key terms: 'economy', 'technology', 'development', 'government', 'resource') and 18 term-concepts have the occurrence frequency above median (only 3 key terms: 'process', 'society', 'production').

The analysis of the key concept 'e-governance' of the interdisciplinary scientific research trend "Digital Economy: e-Governance and Smart Technology" demonstrates the steady development from 8 publications in 2005 to 60 in 2011, and 91 in 2017. Such increase is explained by the implementation of the Program "Digital Economy of the Russian Federation" in 2017. The development of the concept is characterized by stable ties with the term-concepts: 'Internet', 'society', 'governance', 'system', and 'service'.

\subsection{The Technique for the Automated Extraction and Studying Contextual Knowledge: Voyant-Tools}

Firstly, the text array of scientific publications in PDF format were derived from Science Direct (https://www.sciencedirect.com) to search for 'smart technology' distributed by years (2014-2018). Then publications of each year were loaded in Voyant-Tools. Using the Corpus Collocates tool the results of distribution by years in the text array were achieved. The number of publications and the term 'smart technology' according to Science Direct (search on the term 'smart technology') in corpus is: Number of texts $(2014-7,2015-15,2016-29,2017$ - 46, 2018 - 137); Number of terms $(2014-7,2015-20,2016$ $-50,2017-47,2018-210)$.

A graphical representation of the results obtained demonstrated steady growth in publications and the frequency of the term 'smart technology' use (Figure 3). From the data obtained, it has been concluded that in the world scientific discourse there is a sharp increase in interest of the subject 'smart technology'.

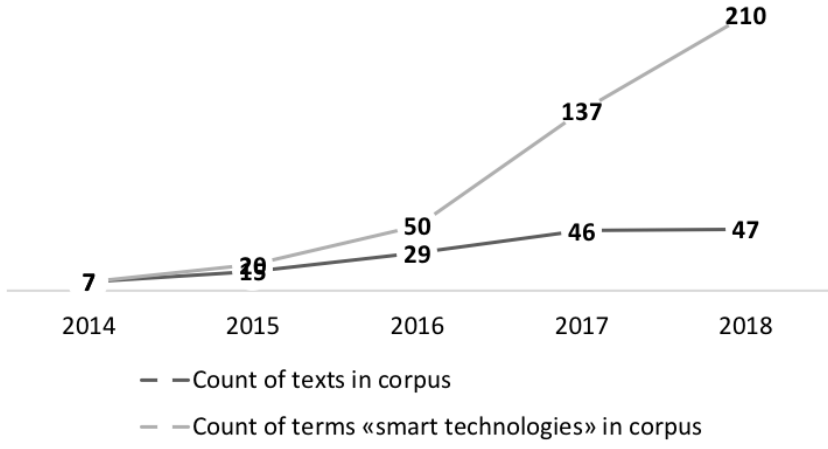

Figure 3. Publications and growth dynamics of the term 'smart technology' according to Science Direct (2014-2018) 
The treatment results of the texts corpus relevant to the main term-concept of 'smart technology' allow making the following conclusions:

- the maximum number of the term 'smart technology' mentions were in 2018. However, the data was incomplete because the corpus was formed at the end of May 2018;

- the combination of 'smart technology' is stable and is uniquely identified by the relevant texts (in 2018);

- the term-concept 'smart technology' is connected with the following terms: 'smart city (cities)', 'smart governance', 'smart infrastructure', 'data processing', 'data analysis', 'data analytics', and 'information systems';

- the term-concept 'smart technology' along with the related terms participate in the formation of the interdisciplinary thesaurus of scientific direction "Digital Economy: e-Governance, and Smart technology".

\section{CONCLUSION}

The main results of the conducted research with the use of the Synthetic Method are the following:

1. There has been formed the list of the key term-concepts, and subject domain of the interdisciplinary scientific direction "Digital Economy: e-Governance and Smart Technology" based on the analysis of the Russian arrays of scientific texts and texts from the Media.

2. There have been conducted studies on the selection of resources based on the identification criteria, influencing the choice, poly-thematic and other significant characteristics.

3. The arrays of the texts have been evaluated on the relevance of the given subject area (testing on the basic keywords).

4. The mechanisms of the terminological landscape formation and extension of the semantic core of the subject domain by the new term-concepts have been elicited.

5. It has been shown the possibility to study the dynamics of digital information resources used with the tools of eLibrary, T-Libra, and Voyant-Tools.

Holding the research of the interdisciplinary scientific trend "Digital Economy: e-Governance and Smart Technology", the authors of the article offer the creation of the contextual knowledge typology: the semantic mapping, standardization and structured description of a disciplinary and interdisciplinary perspective. Such description can be based on general-scientific and common-cultural term-concepts, combining various disciplines. The practical significance of the results is that they can be used to develop and modernize educational programs, as well as to develop and refine actual thesauri of that modern subject domain.

\section{ACKNOWLEDGEMENT}

The reported study is funded by RFBR according to the research project "The integrated approach elaboration to the analysis of the terminological base of the developing interdisciplinary research in distributed network environment” № 18-011-00923, 2018-2020.

\section{REFERENCES}

Bello, L., Clements, N., Dickerson, M., and Hogarth, M., 2016. Critical Collection Analysis: Using DH Tools to Contextualize Historical Collecting Patterns within a Political Framework. Library Staff Publications and Research. 52. Retrieved 10.1.2019, from https://scholarship.claremont.edu/library_staff/52.

Bhargava, N., Rashmi Sharma, R., 2010. Contextualization of Geospatial Database Semantics for Mediating Human-GIS Dialogues. In TECHNIA - International Journal of Computing Science and Communication Technologies, Vol. 3, No. 1, pp. 511-523. 
Bickett, S., Anderson, P. F., Doucette, J., Herring, P. et al., 2017. Text-Mining PubMed Search Results to Identify Emerging Technologies Relevant to Medical Librarians.pdf. Retrieved 10.1.2019, from http://works.bepress.com/pcom_skye_bickett/17/

Chakraborty, J., Rosasco, N., Dehlinger, J., Wadhwaniya, S., Tetali, S. and Gupta, S., 2018. Understanding Cross-Cultural Requirements in mHealth Design: Findings of a Usability Study of Indian Health Professionals. Sezgin E., Yildirim S., Özkan-Yildirim S., Sumuer E. (eds). Current and Emerging mHealth Technologies. Springer, Cham. doi: 0.1007/978-3-319-73135-3_9

Esin, A.B., 2000. Principles and Techniques for the Analysis of a Literary Work. Flint; Science, Moscow, Russia. (In Rissian)

Explanatory Dictionary of the Russian Language by Ushakov D.N. Retrieved 10.1.2019, from http://ushakovdictionary.ru/word.php?wordid=24850. (In Rissian)

Jakubczyc, J. A. and Owoc, M.L., 2011. Contextual Knowledge Granularity. Proceedings of Informing Science \& IT Education Conference (InSITE). Novi Sad, Serbia, pp. 259-268.

Karpov, A.O., 2008. Discourse: Classifications of Contexts. In Questions of Phylosophy. No. 2, pp. 74-87. (In Rissian)

Kononova, O.V., Lyapin, S.Kh. and Prokudin, D.E., 2018. Studying the Interdisciplinary Terminological Landscape of Digital Economy with the Use of Contextual Analysis Tools. In International Journal of Open Information Technologies, Vol. 6, No. 12, pp. 57-66. Retrieved 10.1.2019, from http://injoit.org/index.php/j1/article/view/648/632.

Kravchenko, N.K. Modern Discourse and Discourse Analysis. Concise Encyclopedia of Terminology. Retrieved 10.1.2019, from http://www. sovremennyj-diskurs-i-diskurs-analysis-m-enciklopedija.

Lee, D. C., Markl, M., Dall'Armellina, E., Han, Y., Kozerke, S., Kuehne, T. and Schulz-Menger, J., 2018. The Growth and Evolution of Cardiovascular Magnetic Resonance: a 20-year History of the Society for Cardiovascular Magnetic Resonance (SCMR) Annual Scientific Sessions. In Journal of Cardiovascular Magnetic Resonance, Vol. 20, No. 1, p. 8. doi: 10.1186/s12968-018-0429-Z

Limbu, D.K., Pears, R., Connor, A.M. and MacDonel, S.G., 2006. Conceptual and Concept-Based Interactive Queery Expansion. Proceedings of the $19^{\text {th }}$ Annual Conference of the National Advisory Committee Qualifications (NACCQ). Wellington, New Zealand, pp. 151-155.

Maramba, I.D., Davey, A., Elliott, M.N., Roberts, M., Roland, M., Brown, F., Burt, J., Boiko, O. and Campbell, J., 2015. Web-based Textual Analysis of Free-Text Patient Experience Comments from a Survey in Primary Care. In JMIR Medical Informatics, Vol. 3, No. 2, e20. doi:10.2196/medinform.3783

Rogers, J., 2018. Supporting Research, Public Engagement, and Learning through the Use of Archives in Digital Humanities. Works of the FIU Libraries. Retrieved 10.1.2019, from http://digitalcommons.fiu.edu/glworks/74.

Sampsel, L. J., 2018. Voyant Tools. In Music Reference Services Quarterly, Vol. 21, No. 3, pp. 153-157. doi: 10.1080/10588167.2018.1496754

Shilov, N.G. and Yermolayev, V.I. 2016. Methodological Bases of Intellectual Support for Socially-Oriented Solutions in Flexible Transport Systems. Scientific NSTU Messenger, Vol. 64, No. 3, pp. 59-72. (In Russian)

Sinclair, S. and Rockwell, G., 2015. Text Analysis and Visualization. A New Companion to Digital Humanities. S. Schreibman, R. Siemens and J. Unsworth (eds.). John Wiley \& Sons, Ltd., pp. 274-290. doi:10.1002/9781118680605.ch19

Suchkova, L.I., 2010. Win32 API: Programming Basics: a Tutorial. Barnaul, Russia: AltGTU. (In Russian)

Tenopir, C., Wang, P., Zhang, Y., Simmons, B. and Pollard, R., 2008. Academic Users' Interactions with ScienceDirect in Search Tasks: Affective and Cognitive Behaviors. Information Processing \& Management, Vol. 44, Iss. 1, pp. 105-121. doi: 10.1016/j.ipm.2006.10.007 26

van Dijk, T.A., 2005. Contextual Knowledge Management in Discourse Production. A Cognitive Expantion of Discourse Practice. A New Agenda in Critical Discourse Analysis. R. Wodak and P. Chilton (eds.). John Benjamins Publishing Company, Amsterdam, Netherlands, pp. 71-100.

Verbitsky, A.A. and Kalashnikov, V.G., 2015. A Contextual Approach in Psychology. Psychological Journal, Vol. 36, No. 3, pp. 5-14

Welsh, M. E. 2014. Review of Voyant-Tools. Collaborative Librarianship, Vol. 6, No. 2, p. 96+. 